\title{
Alexandru Busuioceanu en España: poeta y profesor
}

\author{
Mircea Anghelescu \\ Universitatea Bucureşti \\ mircea_anghelescu@yahoo.com
}

\section{RESUMEN ${ }^{1}$}

El escritor rumano, Alexandru Busuioceanu (1896-1961), tras una larga trayectoria como poeta, historiador del arte y ensayista en lengua rumana, es nombrado consejero cultural en Madrid en 1942. Este artículo pretende hacer un repaso de su trayectoria profesional y literaria en España, así como dar cuenta de la percepción que de él tenía la crítica de este país.

Palabras clave: Alexandru Busuioceanu, lengua y literatura rumanas, crítica literaria.

\section{Alexandru Busuioceanu in Spain: poet and teacher}

\begin{abstract}
Romanian author, Alexandru Busuioceanu (1896-1961), had a long trajectory as poet, art historian and essayist in Romanian language when he was appointed cultural counselor in Madrid in 1942. The present article proposes an overview of his professional and literary trajectory in Spain, and also an account of the perception that the critics of this country had of him.
\end{abstract}

Key words: Alexandru Busuioceanu, romanian language and literature, literary criticism.

Relegada a un segundo plano, en general por la actividad de los escritores rumanos del espacio cultural francés, por los escritores que han escrito en francés -algunos célebres, otros, al menos, notorios-, queda la presencia de los literatos rumanos en otros espacios lingüísticos, que han escrito por lo tanto en alemán, en italiano, en

\footnotetext{
${ }^{1}$ Artículo traducido por Laura Eugenia Tudoras.
} 
inglés o en español. Varios son los escritores rumanos que han escrito en español, entre ellos autores muy conocidos como el novelista y ensayista Vintilã Horia (autor, por ejemplo, de la novela Un sepulcro en el cielo, sobre la vida del pintor El Greco) o el comparatista e historiador literario Alexandru Ciorãnescu, de reputación internacional, traducidos a varios idiomas, y siempre editados. Menos conocido, uno de los más interesantes escritores rumanos que escriben en español, es Alexandru Busuioceanu (1896-1961), quien, después de una notable trayectoria como poeta, como historiador del arte y ensayista en lengua rumana, tuvo una última etapa de su vida dedicada a una considerable actividad como poeta y ensayista en lengua española.

Enviado a Madrid en 1942, en calidad de consejero cultural y como profesor de lengua y literatura rumana, Alexandru Busuioceanu no sólo aprovechaba una oportunidad surgida en el ingrato contexto de la guerra mundial, sino que culminaba así una vieja aspiración. Estudiante en Viena, al final de la Primera Guerra Mundial, soñaba, junto con su compañero Grigore Nandriş, futuro lingüista, profesor en Oxford y en Londres, con "huir a España y que nos pierdan la pista" (Busuioceanu 2001: 198) y, en 1948, le confesaba a Alexandru Ciorãnescu: "Creo que he nacido con la nostalgia de la lengua española", y le contaba que se consideraba andaluz gracias a "su romántico abuelo", enamorado de las sombras de la Giralda y del Albaicín. "Su romántico abuelo" era un escritor de periódicos y poeta olvidado de mediados del siglo XIX, Grigore Bossueceanu, originario de Gorj. Éste había viajado mucho a Occidente en los años sesenta de aquel siglo, por Italia y por España. Allí nacen sus versos sobre Granada y el Guadalquivir, publicados en Albumul literar (El álbum literario), personaje sobre el cual su nieto envía una amplia nota biográfica al escritor de periódicos Pamfil aeicaru, en una carta del 5 de enero de 1956 (Cristofor y Pal 2002: 71-73); él reivindicaba así que -sin renegar en absoluto de su origen rumano- se consideraba perteneciente también a la cultura española. Como se puede ver ahora, tenía toda la razón.

$\mathrm{Su}$ poesía, escrita en lengua española y publicada en tres poemarios -Poemas patéticos en 1948, Innominada Luz en 1949 y Proporción de vivir en 1954-, ha sido traducida al rumano por George Ciorãnescu, en un volumen prologado por Alexandru Ciorãnescu y en otro volumen, una antología con un prólogo de Virgil Ierunca, ambos aparecidos en 1963 en Occidente. Estos versos, hoy olvidados, fueron, sin embargo, larga y elogiosamente comentados en el momento de su aparición en las revistas literarias españolas, no sólo en comentarios corteses frente a un poeta extranjero que escribe en la lengua del país de adopción, sino también en comentarios serios de críticos profesionales.

En Cuadernos de literatura, de julio-agosto de 1948, Pablo Cabañas escribe un artículo titulado "Alejandro Busuioceanu, poeta español":

Crítico de arte y profesor de Lengua y Literatura rumana en nuestra Facultad de Letras [de la Universidad Complutense de Madrid], acaba de publicar un libro de poemas en español. Pero lo más extraordinario del caso Busuioceanu es el excepcional dominio de un idioma distinto al suyo natal, hasta el punto de que sus Poemas patéticos, en la espontaneidad, en la naturalidad y en la fluidez de sus imá- 
genes parecen mostrarnos un poeta que escribe en su lengua vernácula. Por eso no dudamos ni un instante en dar al gran escritor rumano Alejandro Busuioceanu el título de poeta español.

Y, después de una amplia presentación del volumen, el crítico vuelve para concluir:

Buen libro éste, con el que Alejandro Busuioceanu ha honrado el panorama de la lírica de nuestros días; libro de profundo contenido emocional, de acentuado simbolismo erótico y panteísta, de exquisita riqueza imaginativa; en los Poemas patéticos, Alejandro Busuioceanu se nos muestra como un brillante poeta español. (Cabañas 1948: 339)

El mismo dominio de la lengua lo observa Bartolomé Mostaza, también en agosto de 1948:

Excelentes piezas líricas éstas que, en un castellano que se diría mamado, brinda el poeta de Rumanía. Forma versolibrista, pero el contenido se ajusta a una expresión clarificada por un noble pensar y por una romántica imaginería [...]. Un mundo elemental, sin paisaje, como de génesis, sirve de fondo armonizador [...]. Recuerda Busuioceanu, por procedimientos y motivaciones, a nuestro Vicente Aleixandre, el máximo campeón acaso de lo que ha dado en llamarse superrealismo, neorromanticismo o existencialismo [...]. (Mostaza 1948)

Bajo el título "Un rumano, poeta español”, Fernández Almagro, de la Real Academia de la Historia, admira la misma destacable calidad poética de una lengua aprendida y no heredada:

Nada de improvisación, pues, en el hispanismo del escritor rumano, y sin forzar demasiado nuestro juicio, por vía analógica cabía hallar cierta relación entre las formas plásticas de la pintura española y la de esta poesía, tan sutil como se quiera, pero corpórea, mórbida, tangible, tal como se realiza en la composición, verbi gratia, titulada Tu cuerpo se encendió en la luz [...]. (Fernández Almagro 1948)

En un artículo que ocupa la página dieciséis entera de la revista La Hora, del 28 de enero de 1949, Eugenio Fratos escribe, bajo el título "El intenso patetismo de Alejandro Busuioceanu":

Este libro del poeta rumano -ya también español- Alejandro Busuioceanu atestigua la presencia de un espíritu en el mundo, es decir, la existencia en la descubierta del mundo de un espíritu singular que con él lucha y se funda, en gigante y patética cosmomagia, oscilando entre la comunión y la distancia. Esto da a su poesía - quiero decir a su agónica creación- esa doble y transmutable vertiente a lo exterior y a lo interior, ese fantasmagórico dinamismo y esa entrevisión de sí y de lo divino, en el entreclamor de que el poeta gusta hablar. (Fratos 1949: 16)

Por supuesto, no pueden faltar al final las apreciaciones con respecto al español del poeta rumano: 
Atestiguar con palabras de una lengua no materna lo que uno es, lo que son las cosas, me parece empresa singular, hazaña, para muy pocos reservada. Busuioceanu ha probado sus fuerzas en harta hazaña y ha vencido. Su mundo poético -que consigo traía- ha podido revelarse, creo que sin menoscabo, en nuestra lengua. (Fratos 1949: 16)

Quizás el más interesante comentario referente a este primer volumen del poeta Busuioceanu lo hace el crítico José Luis Cano, uno de los mejores conocedores de la poesía española de la generación del 36 , tal y como lo caracteriza una reciente enciclopedia, y fundador de la revista Ínsula, en la que Busuioceanu colaboró unos cuantos años; él escribe en "Crónica de poesía", de la revista Ínsula, del 15 de julio de 1948:

Un poeta y escritor rumano que vive hace años en España, Alejandro Busuioceanu, ha intentado una experiencia poética verdaderamente difícil, pero que ha sabido realizar airosamente. Para un poeta, escribir en lengua distinta de la materna, es siempre empresa ardua y llena de peligros, pues no basta con dominar el idioma ajeno, sino que es necesario compenetrarse en el ser poético de esa lengua -ritmo interior y exterior, cadencia del verso, propiedad lírica del vocabulario, etc., es fácil acordarse de Rilke, Milosy o Supervielle escribiendo en francés sus poemas, pero ¡cuántos otros poetas no han fracasado en el intento! Busuioceanu ha querido escribir en castellano sus poemas, y el resultado de su experiencia acaba de ver la luz en un hermoso libro: Poemas patéticos. Difícilmente se adivinaría a un escritor extranjero en el lenguaje poético de este libro [...]. Todo el libro es, en realidad un continuado poema amoroso, en que el poeta habitante de un país latino -el nuestro- canta su dicha y su libertad ganadas en el amor. Pero este amor viene del Norte, de un paisaje de nevados abetos y mares helados, y en el contraste de ese estático país de la amada y el sol ardiente del Sur [...]. (Cano 1948)

Comentada en la prensa en el momento de su aparición, la poesía de Busuioceanu ha sido mencionada por las historias literarias españolas del momento, gozando también del aprecio de entendidos como el poeta Vicente Aleixandre, al respecto de quien se encuentran páginas muy interesantes en el diario de Busuioceanu, anteriormente mencionado, texto desgraciadamente mutilado por el mismo autor antes de su desaparición.

De este modo, el 21 de octubre de 1951, Busuioceanu anota sobre una visita al poeta español que iba a recibir el Premio Nobel un cuarto de siglo más tarde:

Lee unas tres veces el poema. Concluye que es uno de mis fragmentos que más le gustan. Quiere que le lea los fragmentos que todavía no conoce [...]. Insiste, y se los leo. Se muestra entusiasmado [...]. Se muestra sorprendido del estilo de Gong. Cree que es el poema más bonito de los que he escrito hasta ahora. Vuelve a leer, verso a verso, y me dice: "Está escrito, no en castellano, sino en sutilezas de castellano". (Busuioceanu 2001: 79)

E1 27 de octubre anota sobre una nueva visita a Vicente Aleixandre, el debate de los textos, las apreciaciones sobre los versos - "Está encantado con el fragmento 
Creación, lo relee [...]. Cuenta entre los fragmentos que prefiere Yo y yo y Claridad intangible [...]"-. Cuando Busuioceanu le confiesa no tener la intención de continuar escribiendo poesía en español Aleixandre protesta: "Grandes protestas. Ánimos insistentes para continuar" (Busuioceanu 2001: 87-88).

Otro escritor rumano que ha vivido en España y ha escrito también en español, Vintilã Horia, compara esta poesía con una gnosis y ve en ella "una dualidad precristiana, o antecesora, una especie de continua oscilación entre día y noche, entre pureza y pecado, entre carne y espíritu, entre sombra y luz... con una evidente inclinación a concederle a la sombra la última palabra [...]”. En el pesimismo de la poesía de Busuioceanu, Vintilã Horia (que ha escrito una crónica del volumen Proporción de vivir) encuentra también versos que recuerdan a los de Eminescu, remitiendo a Rugãciunea unui dac (La oración de un dacio) o Scrisoarea I (Carta I): "No había sombra porque forma no había" (Horia 1954: 192-195).

Claro, le compete al lector español decir si los versos, a menudo herméticos, de la poesía de Busuioceanu siguen significando hoy algo o no. Quedan, sin embargo, bastantes cosas que decir sobre su actividad como crítico y ensayista en lengua española después de la conferencia con la que inaugura su mandato en 1943, publicada inmediatamente en un folleto titulado Dacios y romanos en los Cárpatos, o sobre los estudios de historia literaria entre los cuales el más conocido es el que versa sobre Juan Valera y Lucia Paladi, marquesa de Bedmar; el artículo está escrito en base a unos documentos proporcionados por los descendientes del escritor español y ha recibido no sólo apreciaciones por parte de los especialistas, sino también un premio literario español (el estudio apareció parcialmente también en rumano).

Busuioceanu también ha publicado más de treinta ensayos en la revista Ínsula, editada en Madrid entre 1946 y 1980, que son muy poco o en absoluto conocidos ${ }^{2}$. Publicados la mayoría de las veces en la octava y última página de la revista, en una columna propia llamada "Letra y espíritu", estos ensayos comentan la literatura desde el punto de vista de un escritor profesional, que se siente atraído por la meditación acerca de la condición de la escritura y se muestra sensible ante lo novedoso.

En sus ensayos se hace visible la preferencia por las técnicas modernas, por la expresión cifrada que se tiene que desprender de la materia del sentimiento, digna de desprecio porque la rebaja. Entre los españoles, admira a Ortega y Gasset, a Juan Ramón Jiménez y, sobre todo, a Eugenio d'Ors, de quien comenta con entusiasmo, en varios fascículos, la pieza Guillermo Tell, vista en una representación inusual, una lectura pública sin decorado que facilita la extracción de los sentidos esenciales, "que crea una ilusión inesperada y encarna, no la diversidad de la realidad, sino el antagonismo de las ideas y aquel fatum de los seres en eterno enfrentamiento social" (Busuioceanu 1949), ideas seguidas no sólo aquí sino también en la poesía, donde elogia a un imitador de Mallarmé como Landínez, pero, sobre todo, el conocimiento intuitivo, total, denominado "epifanismo", con un término utilizado al

\footnotetext{
${ }^{2}$ La revista, muy interesante en general, incluye también una referencia a Eminescu: Marcos Ricardo Barnatan, "Mihail Eminescu: poesía extranjera en España", en junio de 1974.
} 
mismo tiempo por un grupo de intelectuales franceses que se opone al colectivismo marxista y, en general, a las ideologías de izquierda.

Poco conocido hoy, el epifanismo ha sido un movimiento artístico y literario, con influencias sobre todo en la poesía, lanzado a través de la publicación de un manifiesto en la revista parisina Arts, en marzo de 1948, que consigue rápidamente adeptos en Francia, en Bélgica, en los países nórdicos, en América del Sur, en los países del norte de África. Implica un individualismo que rechaza el "compromiso" a toda costa, en una época en la que se cultivaban los compromisos; se opone al existencialismo de Sartre, al que ataca de forma directa y, en general, a las ideas que tienden a la marxificación, propagadas por el movimiento intelectual francés de izquierdas, muy potente en aquella época. El epifanismo, que desea suceder a las grandes escuelas de la vanguardia, es, en sus distintas versiones difundidas en la época, un movimiento que intenta acercar las artes plásticas a la literatura y otorgar un papel superior a la intuición. En Francia, el más conocido y activo de sus militantes es Henri Perruchot, autor de numerosas biografías de artistas plásticos y de escritores, que había publicado en 1949 un artículo con el elocuente título de "Le marxisme, destructeur de l'homme", así como la revista Arts. Según Perruchot, autor del Manifest de l'épiphanisme, "l'épiphanisme exprime une volonté d'évasion hors de ces philosophies du désespoir qui ont cours aujourd'hui [...]. L'existentialisme ne peut en ses conséquences logiques conduire qu'au suicide [...]". En España, Busuioceanu, que quizás conocía la agrupación ideológica francesa, ha negado que su epifanismo, estrictamente literario, tuviera relación alguna con el epifanismo más conocido de los escritores individualistas de París, en un artículo en el número 41 de la revista Ínsula (15 de mayo de 1949).

Mencionado primero en relación con la poesía de Vicente Aleixandre, el epifanismo es para Busuioceanu un movimiento revelador, un "mecanismo propio de la razón poética cuyo instrumento irreductible es la metáfora". Emplea el término de metáfora en "el sentido más simple de la lógica poética, para facilitar la comprensión de la idea". La poesía moderna es "como una metáfora elevada al cuadrado o al cubo" y su término medio lo expresa sólo en la síntesis final. Aparte de los poetas españoles, Busuioceanu escribe sobre los escritores europeos del momento, marcando las mismas preferencias e introduciendo, en un país todavía tradicionalista en gustos, el nombre y la obra de unos escritores considerados entonces innovadores como, por ejemplo, André Frénaud, Jean Paulhan, Joe Bousquet, Louis Aragon, Pierre-Jean Jouve y otros, sin olvidar tampoco a Eliade (con la traducción francesa de Maitreyi).

Probablemente estos textos debían incluirse en un volumen de "ensayos" que Busuioceanu anunciaba en 1954 en la portada de la revista Destin como "en preparación"; pero como el volumen no apareció, quizás alguien debería recuperarlos de las páginas de las revistas Ínsula, Escorial, probablemente otras también, y ponerlas de nuevo en circulación para fijar también este episodio de la cultura rumana en España, factor moderno y democrático en unos tiempos bastante oscuros.

En Rumanía, y en general entre los rumanos, sobre todo entre los intelectuales del exilio, los ecos más amplios e importantes de las diversas actividades los han tenido las publicaciones fragmentadas y luego la edición íntegra aparecida en Buca- 
rest en 1985, del estudio Zamolxis sau mitul dacic în istoria şi legendele spaniole (Zamolxis o el mito dacio en la historia y las leyendas españolas); un fragmento titulado Historia y destino apareció también en español en 1953. Se trata de un estudio que revela la existencia en la obra de los primeros historiadores españoles de unas informaciones sobre dacios, godos y getas. Esto demuestra que informaciones sobre los dacios, sobre sus dioses, sobre sus reyes y sus sacerdotes, llegan a los antiguos textos históricos, empezando con Isidoro de Sevilla, como godos. De este modo, como afirma el mismo autor, "la leyenda ha prosperado, ha echado raíces en todas las crónicas, y la historia de los dacios, de forma fabulada, ha entrado como un capítulo que alcanza la misma historia de España”. Como le dice Mircea Eliade al autor en una carta enviada después de la lectura del texto fragmentado aparecido en la revista Destin, publicación de los exiliados rumanos en España: "El estudio es pura y simplemente extraordinario. Abre perspectivas insospechadas para la comprensión y valorización de los mitos históricos medievales y no sólo en nuestro caso, es decir en Europa [...]. Sería una lástima que semejante descubrimiento quedara enterrado en una revista de circulación limitada".

Si la actividad literaria propiamente dicha del poeta y ensayista Alejandro Busuioceanu no es desconocida ni en España ni en Rumanía, la de organizador cultural y promotor de las relaciones culturales hispano-rumanas es conocida sólo superficialmente. Aunque existía cierta simpatía entre los pueblos español y rumano, que expresan a veces los escritores de ambas naciones, la decisión de crear un instituto rumano en España y la llegada de Busuioceanu como enviado a Madrid es el resultado de una necesidad de conocimiento que ha madurado con el tiempo. Busuioceanu mismo lo recuerda en una conferencia:

Las relaciones intelectuales entre España y Rumanía son lo suficientemente antiguas y se han producido espontáneamente, unas veces como resultado de los acontecimientos políticos, otras veces por un interés puramente intelectual o una simpatía natural entre países tan afines. Pero la distancia entre los dos países, su aislamiento en las extremidades de unas vías que no los unían directamente ni por la circulación, ni por ritmo intelectual, han hecho que estos lazos fuesen muy variables, no siempre recíprocos y quizás tampoco orientados. De aquí ha resultado la necesidad de organizar relaciones más estrechas, de extenderlas y dirigirlas para hacerlas lo más eficaces y esenciales.

Así se llegó a la idea del Convenio Cultural, firmado entre España y Rumanía hace dos años y cuyos frutos empiezan a hacerse sentir. En virtud de este Convenio se ha creado la Cátedra de Lengua y Literatura Rumanas inaugurada en diciembre de 1942 en la Universidad, cátedra que ha reunido, desde el principio, un número apreciable de alumnos. (Fondo Busuioceanu, dos. 122, f. 115)

Delegado del Ministerio de Asuntos Exteriores rumano, enviado para ocupar el puesto de consejero cultural de la embajada rumana en el verano de 1942 y para organizar y dirigir el recién fundado Instituto Cultural Rumano en Madrid, lo que suponía también dirigir un lectorado de lengua y literatura rumana en la Universidad de Madrid, Alexandru Busuioceanu comienza su actividad pública antes, con la organización de una exposición del libro y de la prensa rumana en Barcelona. 
Busuioceanu es quien ha organizado y ha dirigido en sus primeros años el antecesor del Instituto Cultural de hoy, el Instituto Cultural Rumano de Madrid, inaugurado el 17 de diciembre de 1942 con una ceremonia en la que participaron personalidades conocidas de la vida diplomática y cultural madrileña. Es el momento de mencionar que a estas manifestaciones oficiales y recepciones ofrecidas por el Instituto Cultural Rumano, en el período en el que fue dirigido por Busuioceanu, acudían las más relevantes personalidades del momento. En una recepción ofrecida en el período de preparación de la inauguración del Instituto Rumano, el 4 de noviembre de 1942, con motivo de la visita del profesor rumano N. I. Herescu, conocido latinista, una personalidad cultural sin comisionados políticos, estuvieron presentes José Casares Gil, presidente de la Academia de Ciencias, Eugenio d'Ors, el rector y el vicerrector de la Universidad de Madrid, otros diplomáticos extranjeros y rumanos (entre los que se cuenta Mircea Eliade), directores de institutos similares de Madrid, periodistas, etc.

La conferencia que marcó la inauguración del Instituto fue titulada Los orígenes y la latinidad del pueblo rumano y fue impartida por el nuevo director de la institución, Alexandru Busuioceanu. Se trata de una conferencia de carácter general y compilatorio, que debía presentar ante los invitados "las cartas de recomendación" de la latinidad del pueblo rumano y la antigüedad de sus opciones europeas. El texto de la conferencia, que se conserva manuscrito, puede ser considerado también una lección de apertura del curso de historia y cultura rumanas de la Facultad de Filosofía y Letras. Empieza con la mención de la primera conferencia sobre el origen latino del pueblo rumano, sostenida en Madrid en 1868 ante el decano de la Facultad de Letras, ante los profesores y los estudiantes, por el estudiante rumano Andrei Vizanti. Y, a continuación, Busuioceanu define así los objetivos de su curso: "hablar a los estudiantes españoles sobre la lengua de mi patria, sobre la historia, sobre la cultura, sobre sus monumentos; mostrarles las relaciones de origen y de espiritualidad que nos acercan al noble pueblo español e intentar hacerles comprender y querer este otro mundo latino, situado al otro lado de Europa y fecundado, en sus mismas fuentes, por la sangre y por el espíritu hispánico".

El desarrollo de las relaciones culturales entre los dos pueblos y países es apoyado por la fundación de la cátedra de lengua y literatura rumana en Madrid y de la de lengua y literatura española en Bucarest, activa desde 1930. Si los dos países se encuentran a una distancia máxima en la geografía de Europa, su espíritu está emparentado y es a través de la cultura, como mejor y más fácilmente se puede realizar su acercamiento.

En realidad, los cursos de esta especialización son seguidos por un número impresionante de estudiantes de filología románica: en 1943 había 43 y en 1944 había 61, según los registros encontrados entre los documentos oficiales del archivo Busuioceanu. Desde 1943, ante la recomendación de los profesores de la facultad, entre los cuales hay romanistas conocidos como Dámaso Alonso y otros, la sección de rumano adquiere el mismo estatuto que las otras lenguas románicas estudiadas (el francés, el italiano y el portugués), es decir, es frecuentada por estudiantes de tercer y cuarto curso, que pueden escoger el rumano como segunda lengua obligatoria para el examen final. 
Según los mismos documentos del archivo Busuioceanu, el programa establecía en el año 1944 clases diarias, por las tardes desde las seis hasta las ocho, en el Instituto Cultural Rumano: el lunes había clases de gramática rumana y de historia de la cultura rumana, cada una con una duración de una hora, impartidas por el lector Paul Georgescu; el martes, en el mismo horario, un seminario de lengua rumana y, luego, otra clase de literatura rumana, ambas impartidas por el profesor Busuioceanu; el miércoles se realizaban "trabajos del diccionario rumano-español" con el profesor Busuioceanu (las fichas de las primeras tres letras de este diccionario se encuentran también en el archivo); el jueves se impartía una primera clase de gramática y luego otra de trabajos prácticos (ejercicios), ambas con Paul Georgescu, y el viernes se trabajaba en el diccionario, esta vez con el lector Paul Georgescu. Aunque las clases de literatura rumana son muy reducidas en el horario aquí citado, la enseñanza de esta materia debió de haber ocupado un lugar más importante del que aparece reflejado en la planificación, porque estas clases han constituido el origen del compendio de historia de la literatura rumana que ha dejado Busuioceanu, aparecido en español en 1946, traducido al rumano y publicado apenas en 1998 en Bucarest. Es muy probable que en el Instituto se celebraran sobre todo seminarios y trabajos prácticos para los cuales resultaba útil la amplia biblioteca, constituida gracias al esfuerzo y al empeño de su director, y que en el local de la facultad se impartieran las clases propiamente dichas.

La biblioteca del Instituto fue dotada desde el principio, acción empezada antes de la inauguración y continuada posteriormente, con muchos libros, discos, mapas, fotografías y otros materiales ilustrativos, enviados desde Bucarest: clásicos de la literatura rumana y traducciones a lenguas de circulación, pero también algún ejemplar de más recientes o más antiguas traducciones rumanas de algunos autores españoles, grabaciones de música folclórica y baladas rumanas, música clásica y para concierto en discos de vinilo y partituras, etc. La biblioteca del Instituto estaba abierta a diario, mañana y tarde, sirviendo tanto a los estudiantes como a los lectores ajenos al sistema de enseñanza.

Como se puede observar, ya desde su fundación, el Instituto ha desempañado un papel complejo y ha actuado en dos frentes, público y universitario, situación debida, en primer lugar, al doble cargo de su director, tanto como diplomático cultural dentro de la embajada rumana como en calidad de profesor agregado de universidad. Esta situación, poco habitual, hace necesario precisar los objetivos con los que ha sido fundado el Instituto, más amplios y más ambiciosos que los de los institutos similares de Madrid, el francés o el italiano, por ejemplo, cuyos programas han servido, sin embargo, de modelo al Instituto Rumano (se encuentran en los dossieres referentes a la fundación de este Instituto).

Con la elocuencia que nace de la sinceridad, en una conferencia sobre "Las relaciones históricas e intelectuales entre España y Rumanía", del 23 de marzo de 1944, Alexandru Busuioceanu respondía en primer lugar a una posible pregunta: ¿por qué surgió la necesidad de fundar un instituto de cultura rumana en España?

¿Por qué hemos hecho un Instituto Rumano en Madrid? Es una pregunta que podría plantearse por quien conoce poco a Rumanía, sus orígenes y su historia, su 
espíritu latino, sus ideales de cultura y, sobre todo, su sentimiento de cariño y admiración para el gran pueblo español, que tan brillantemente representa el genio latino en el mundo.

Yo, a esto, contestaría con otra pregunta: ¿Por qué no hemos hecho hace tiempo ya este Instituto?

Un Instituto de Cultura, de esta clase, es decir, consagrado a la enseñanza y organización de relaciones intelectuales y artísticas, es una institución de acercamiento, que se funda en un elemento de simpatía y un deseo sincero, en una necesidad de conocimiento recíproco.

En la misma conferencia explica de nuevo, dos años más tarde, los objetivos con los cuales ha sido creado el Instituto Cultural Rumano de Madrid y los medios a través de los cuales su director pretendía conseguirlos desde un principio:

El fin de este Instituto era ser el órgano permanente de acercamiento cultural entre España y Rumanía, desarrollando su actividad en todos los terrenos intelectuales y manteniendo relaciones con las instituciones y personalidades culturales de ambos países.

Su programa es amplio y reflexionado: organizar un centro de documentación, constituido por la biblioteca del Instituto que será dotada para poder informar sobre Rumanía y los problemas del Oriente europeo en relación con Rumanía y por un servicio de documentación referente a Rumanía y a las relaciones hispanorumanas; establecer contacto con Universidades y las instituciones de alta cultura de los dos países, iniciando y facilitando relaciones, intercambios y colaboraciones. Tendrá en cuenta sobre todo la dotación de las bibliotecas españolas con libros rumanos concernientes a Rumanía y la organización de cambios de publicaciones; organizar cursillos y conferencias, invitando con este fin a profesores y conferenciantes españoles y rumanos; colaborar con las Universidades e instituciones españolas de alta cultura, organizar intercambios de profesores y estudiantes; ser el órgano de coordinación de la actividad de los profesores y lectores rumanos en las Universidades españolas y dirigir la actividad de los estudiantes rumanos en España; organizar visitas de intelectuales para facilitar el acercamiento y conocimiento recíproco entre los dos países; con el mismo fin, organizar manifestaciones artísticas rumanas en España y españolas en Rumanía; facilitar traducciones y ediciones de obras literarias rumanas o de estudios sobre Rumanía en lengua española, editar una colección de publicaciones literarias y un anuario científico del Instituto, etc.

Con la colaboración de los estudiantes españoles, el director del Instituto pensaba también componer el primer diccionario rumano-español, y otras.

Difícilmente se pueden apreciar hoy los resultados de esta acción que había movilizado importantes fuerzas intelectuales y materiales en tiempos de guerra cuando, según la célebre cita conocida desde Cicerón, inter arma, silent musae. El comienzo de la actividad, el programa de los cursos, algunas de las conferencias impartidas en el Instituto Cultural Rumano, fueron anunciados por los periódicos madrileños, en notas redactadas por sus funcionarios o, muy probablemente, por el 
mismo Busuioceanu, que era un meticuloso organizador: en los archivos del estado se conservan planos detallados para la distribución de las salas del Instituto, para la ubicación de los invitados en la mesa en distintas ceremonias, notas y resguardos de la adquisiciones de bienes para el Instituto, etc.

No sé si la historia de las relaciones diplomáticas de mi país reclama para sí hoy este pasado cultural que ha significado, en estas circunstancias, al igual que en otras, un apoyo esencial para el conocimiento de Rumanía en el mundo y para el establecimiento de relaciones duraderas con un mundo al que estamos unidos a través de miles de vínculos. La literatura rumana reivindica, sin embargo, la personalidad de Alexandru Busuioceanu y de otros hombres de cultura como él, ensayistas, críticos de arte, profesores, cuya actividad fuera de Rumanía ha hecho posible un mejor conocimiento de su país, cada vez mejor y más fructuoso, incluido nuestro encuentro de aquí y de ahora.

\section{BIBLIOGRAFÍA}

Los documentos del archivo Busuioceanu se han citado siguiendo los dossieres existentes en el Fondo Busuioceanu de los Archivos Centrales del Estado, Bucarest.

BUSUIOCEANU, Alexandru (1949): "Para un teatro impopular". Ínsula, núm. 38, 15 de febrero de 1949.

- (2001): Caietele de miezul noppii. Edición, notas, traducción y prefacio de C. PopescuCadem. București: Jurnalul literar.

CABAÑAS, Pablo (1948): “Alejandro Busuioceanu, poeta español”. Cuadernos de Literatura, vol. III, núm. 8-9, julio-agosto de 1948, p. 339.

CANO, José Luis (1948): “Crónica de poesía”. Ínsula, del 15 de julio de 1948.

CRISTOFOR, Ion; y PAL, Maria (eds.) (2002): Memoria exilului românesc. Prefacio de Ion Cristofor. Cluj: Napoca Star.

FERNÁNDEZ ALMAGRO, Melchor (1948): "Un rumano, poeta español”. La vanguardia española.

FRATOS, Eugenio (1949): "El intenso patetismo de Alejandro Busuioceanu". La Hora, 28 de enero de 1949, p. 16.

HORIA, Vintilã (1954): “Alexandru Busuioceanu: Proporción de vivir”. Destin, cuaderno 89, mayo 1954, pp. 192-195.

MOSTAZA, Bartolomé (1948): “Alejandro Busuioceannu”. Ya, 4 de agosto de 1948.

PERRUCHOT, Henri (1949): Introduction à l'épiphanisme. Paris: Le Sillage. 